\title{
Smoking as a precipitating factor for migraine: a survey in medical students
}

\author{
L. López-Mesonero $\cdot$ S. Márquez $\cdot$ P. Parra $\cdot$ \\ G. Gámez-Leyva $\cdot$ P. Muñoz $\cdot$ Julio Pascual
}

Received: 1 December 2008/ Accepted: 12 January 2009/Published online: 31 January 2009

(C) Springer-Verlag 2009

\begin{abstract}
Our aim was to analyse the relationship between migraine and smoking in medical students. Medical students who had already received teaching on migraine were asked to answer an ad hoc questionnaire. A total of 361 students filled in the questionnaire: 245 (68\%) were women. International Headache Society criteria were fulfilled by 58 (prevalence of migraine $16 \%$ ) students. A total of $74(20 \%)$ were current smokers: 21 males (18\% of men were smokers) and 53 females (22\% smokers). Within those 58 students with migraine, 17 (29\%) smoke: only 2 were males (14\% of males with migraine smoked) while the remaining 15 were females (34\% of women with migraine smoked). Within those 17 students who were smokers and migraineurs, $12(71 \%)$ thought that smoking worsens migraine and $10(59 \%)$ that smoking precipitates attacks. The minimum number of cigarettes which subjectively precipitates attacks was 5 . Migraine prevalence in the 20 s in Spain is $16 \%$. Our data obtained in medical students suggest that smoking can be a precipitating factor for migraine attacks, as the prevalence of active smoking is one-third higher in migraineurs and as there seems to be a
\end{abstract}

L. López-Mesonero · S. Márquez · P. Parra

Faculty of Medicine, University of Salamanca, Salamanca, Spain

G. Gámez-Leyva

Service of Neurology, University Hospital of Salamanca,

Salamanca, Spain

P. Muñoz

Primary Health Care Management, Santander, Spain

J. Pascual ( $\square)$

Service of Neurology, University Hospital Marqués de

Valdecilla, 39008 Santander, Spain

e-mail: juliopascual@telefonica.net relationship between the number of cigarettes and the development of migraine attacks.

Keywords Migraine $\cdot$ Smoking

\section{Introduction}

Migraine is a frequent condition suffered from 10 to $15 \%$ of the population [1]. The prevalence of smoking is also very high, world average of smoking cigarettes reaching $30 \%$. Migraine attacks can be elicited by a variety of precipitants: such as psychological events, weather changes or specific food or drinks. The relationship between migraine and smoking is controversial. The aim of this study was to further analyse the relationship between migraine and smoking in a population of medical students.

\section{Subjects and methods}

Students from the Faculty of Medicine of the University of Salamanca, Spain were asked to answer an ad hoc questionnaire to analyse the possible relationship between migraine and smoking. The study was approved by the local ethics committee. All medical students had already received specific teaching on migraine diagnosis according to the International Headache Society (IHS) criteria [2]. The questionnaire included a remainder of the IHS diagnostic criteria for migraine without aura. The presence of aura was not specifically investigated. Students were asked to fill in first their demographic data, detailed current and historical smoking habits and if they fulfilled or not criteria for migraine diagnosis. Those who met criteria for IHS migraine were asked to answer a few more questions: (1) 
what is the average frequency of migraine attacks? (2) do you think that smoking worsens or precipitate migraine?; and (3) if smoking worsens migraine, from how many cigarettes do you think are necessary to precipitate or aggravate migraine?

\section{Results}

A total of 361 medical students filled in the questionnaire: $245(68 \%)$ were women and $116(32 \%)$ men. The age range was 19-26 years. IHS migraine criteria were fulfilled by 58 (global prevalence of migraine 16\%) medical students (prevalence in males 12\% and in females 18\%). A total of $74(20 \%)$ students were current smokers: 21 were males (18\% of men were smokers) and 53 females (22\% of women were smokers). Within those 58 medical students with migraine, 17 (29\%) smoked $(P=0.05$; OR 0.97-3.90 vs. total smokers). Only 2 were males (14\% of males with migraine smoked) while the remaining 15 were females (34\% of women with migraine smoked). The frequency of migraine attacks is illustrated in Fig. 1. Migraineurs with a high frequency of attacks (more than one attack per month) were numerically lower $(P=0.058)$ in the group of nonsmokers (56\%) as compared with smokers (77\%).

Regarding the number of cigarettes, $77 \%$ of the medical students with migraine and $80 \%$ of those without migraine smoked fewer than 10 cigarettes per day. Within those 17 students who were both smokers and migraineurs, 12 (71\%) think that smoking worsens migraine and 10 (59\%) that smoking precipitates migraine attacks. The number of cigarettes which subjectively precipitates migraine attacks appears in Fig. 2.

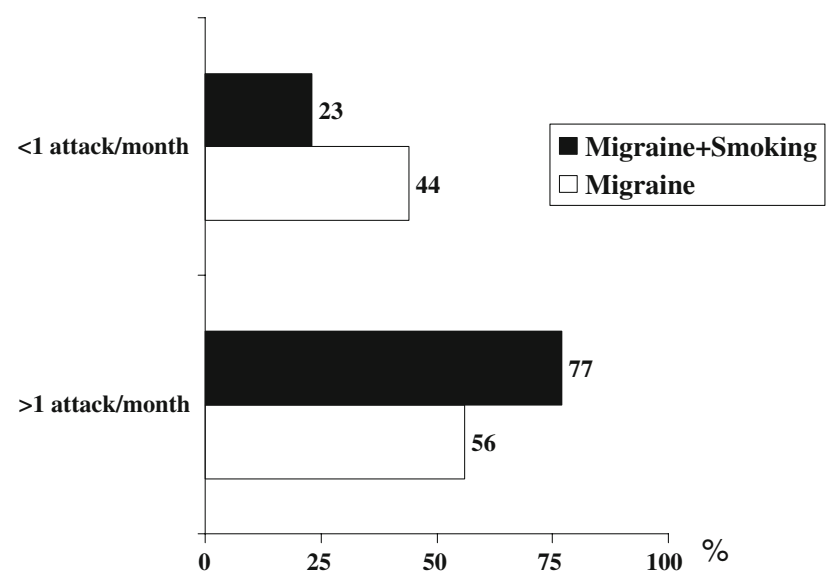

Fig. 1 Frequency of migraine attacks in migraineurs who were smokers versus those who did not smoke. Notice that smokers showed a higher frequency of migraine attacks versus non-smokers

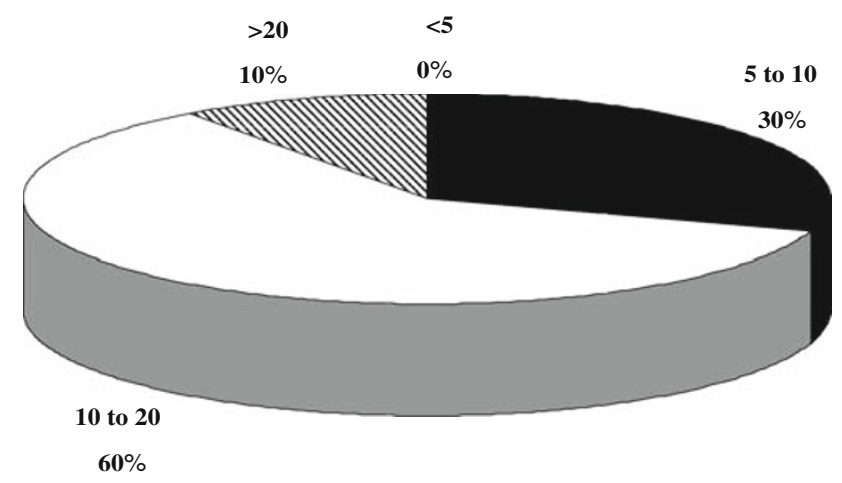

Fig. 2 Number of cigarettes per day which subjectively could precipitate a migraine attack in the students' opinion. No subject thought that less than five cigarettes could precipitate an attack

\section{Discussion}

Even though it was not the main objective of this study, our data confirm previous results obtained in our country regarding migraine prevalence $[1,3]$. According to our questionnaire, prevalence of migraine in the 20s in Spain is $16 \%$ (12\% in males and 18\% in females). These data seem to be very reliable as all participants were medical students who had received specific and recent teaching on migraine diagnosis.

Our main objective was to further analyse the relationship between migraine and tobacco use. From our data, there seems to be some relationship between smoking and migraine. First, even though statistical significance was not reached due to the relatively low numbers of smokers and migraineurs, prevalence of smokers was almost one-third higher in migraineurs (29\%) as compared to non-migraineurs $(20 \%)$. This was clear for women: $22 \%$ of female students were smokers as compared to $34 \%$ of female students with migraine. Results were not confirmed for males, possibly due to the current low frequency of males both as medical students and as smokers as compared to females in Spain. Second, at least subjectively, most migraineurs thought that smoking cigarettes was a precipitant or aggravating factor for the development of migraine attacks. And finally, our medical students clearly pointed out to a direct relationship between the number of consumed cigarettes and the precipitation of migraine attacks, which concurs with previous observations $[4,5]$ and with our finding that those migraineurs who smoked showed a higher frequency of migraine attacks. Interestingly, no student with migraine thought that smoking fewer than five cigarettes daily was capable of developing a migraine attack.

In contrast to what happens in cluster headache where smoking has been found to be more frequent and extensive than in controls [6-9], the relationship between migraine and cigarette smoking is controversial. There are a few studies analysing this potential relationship. In general, 
these studies identified a high proportion of smokers in migraine subjects, but most of them were carried out before the availability of IHS diagnostic criteria and did not include a control group of matched non-smokers [10-16]. In the most important study in this field, Chen et al. studied in 1987508 women who had migraine and 3,192 control women with no migraine history [10]. In their series, there were significantly more smokers in the migraine women when compared with non-migraineurs (64 vs. 55\%). Two more recent studies, in Denmark [11] and Japan [12], could not confirm an association between migraine and smoking cigarettes. The Danish study; however, did not include a control group and the Takeshima et al. work was not designed specifically to analyse the influence of smoking. In fact, they gave no details on the questions on tobacco use that were asked to the participants or regarding the proportion of subjects who were smokers. Interestingly, however, smoking was considered a precipitant factor for migraine headache by $3.3 \%$ of migraine without aura subjects as compared of only $1.7 \%$ of tension-type headache.

The mechanisms underlying a potential relationship between cigarette consumption and migraine are unknown. Explanations include: an enhancing effect of smoking on the activity of brain monoamines, a decrease in nitric oxide production, nicotine dependence [17-19] or the known comorbidity of migraine with psychiatric disorders, such as depression, where smoking prevalence has been shown to be increased in some studies [20]. Osmophobia to cigarettes, not investigated in our questionnaire, could also act as a precipitating factor for migraine attacks [21]. In fact, cigarette smoke was identified as an offending odour by more than half of migraineurs in a recent survey [22]. An alternative explanation could be that smoking craving could be one prodromal symptom similar to what happens for some foods and not a real precipitating factor [23]. This possibility seems improbable; however, as in most cases smoking craving was present not only in direct relationship with a migraine attack but also in the pain-free period.

In conclusion, our data obtained in medical students suggest that smoking cigarettes can be a true precipitating factor for migraine attacks, as the prevalence of active migraine is higher in migraineurs versus non-migraineurs and as there seems to be a relationship between the number of smoked cigarettes and the development of migraine attacks.

\section{Conflict of interest None.}

\section{References}

1. Stovner LJ, Zwart JA, Hagen K, Terwindt GM, Pascual J (2006) Epidemiology of headache in Europe. Eur J Neurol 13:333-345
2. Headache Classification Committee of the International Headache Society (2004). The International Classification of Headache Disorders. 2nd edn. Cephalalgia 24(Suppl 1):1-160

3. Laínez MJA, Vioque J, Hernández-Aguado I, Titus F (1994) Prevalence of migraine in Spain. An assessment of the questionnaire's validity by clinical interview. In: Olesen J (ed) Frontiers in headache research: headache classification and epidemiology. Raven Press, New York, pp 221-225

4. Celik Y, Ekuklu G, Tokuc B, Utku U (2005) Migraine prevalence and some related factors in Turkey. Headache 45:32-36

5. Vlajinac H, Sipetic S, Dzoljic E, Maksimovic J, Kostic V (2003) Some lifestyle habits of female Belgrade university students with migraine and non-migraine headache. J Headache Pain 4:67-71

6. Hannerz J (1997) Symptoms and diseases and smoking habits in female episodic cluster headache and migraine patients. Cephalalgia 17:499-500

7. Kudrow L (1980) Cluster headache: mechanisms and management. Oxford University Press, New York

8. Manzoni GC, Bono G, Lanfranchi M, Micieli G, Martucci N, Nappi G (1983) Lithium carbonate on cluster headache: assessment of its short- and long-term therapeutic efficacy. Cephalalgia 3:109-114

9. Sjaastad O (1992) Cluster headache syndrome. Saunders, London

10. Chen TC, Leviton A, Edelstein S, Ellenberg JH (1987) Migraine and other diseases in women of reproductive age. The influence of smoking on observed association. Arch Neurol 44:1024-1028

11. Rasmussen BK (1993) Migraine and tension-type headache in a general population: precipitating factors, female hormones, sleep patterns and relation lifestyle. Pain 53:65-72

12. Takeshima T, Ishizaki K, Fukuhara Y, Ijiri T, Kusumi M, Wakutani Y et al (2004) Population-based door-to-door survey of migraine in Japan: the Daisen study. Headache 44:8-19

13. Spierings ELH, Ranke AH, Honkoop PC (2001) Precipitating and aggravating factors of migraine versus tension-type headache. Headache 41:554-558

14. Payne TJ, Stetson B, Stevens VM, Johnson CA, Penzien DB, van Dorsten B (1991) The impact of cigarette smoking on headache activity in headache patients. Headache 31:329-332

15. Mannix LK, Frame JR, Solomon GD (1997) Alcohol, smoking, and caffeine use among headache patients. Headache 37:572-576

16. Volans GN, Castleden CM (1976) The relationship between smoking and migraine. Postgrad Med J 52:80-82

17. Littlewood JT, Glover V, Sandler M, Petty R, Peatfield R, Clifford-Rose F (1984) Migraine and cluster headache: links between platelet monoamine oxidase activity, smoking and personality. Headache 24:30-34

18. Lassen LH, Ashina M, Christiansen I, Olesen J (1997) Nitric oxide synthase inhibition in migraine. Lancet 349:401-402

19. Fowler JS, Volkow ND, Wang GJ, Pappas N, Logan J, MacGregor R et al (1996) Inhibition of monoamine oxidase B in the brains of smokers. Nature 379:733-738

20. Fergusson DM, Goodwin RD, Horwood LJ (2003) Major depression and cigarette smoking: results of a 21-year longitudinal study. Psychol Med 33:1357-1367

21. Zanchin G, Dainese F, Mainardi F, Mampreso E, Perin C, Maggioni F (2005) Osmophobia in primary headaches. J Headache Pain 6:213-215

22. Zanchin G, Dainese F, Trucco M, Mainardi F, Mampreso E, Maggioni F (2007) Osmophobia in migraine and tension-type headache and its clinical features in patients with migraine. Cephalalgia 27:1061-1068

23. Quintela E, Castillo J, Muñoz P, Pascual J (2006) Premonitory and resolution symptoms in migraine: a prospective study in 100 unselected patients. Cephalalgia 26:1051-1060 